\title{
Development of an Interactive Role Play Game (RPG) to Improve Early Childhood Digital Literacy
}

\author{
Rakimahwati Rakimahwati ${ }^{1}$, Desmawati Roza ${ }^{2}$ \\ Department of Early Childhood Education, Universitas Negeri Padang ${ }^{1,2}$ \\ \{rakimahwati10@yahoo.com $\left.{ }^{1}\right\}$
}

\begin{abstract}
Children's social-emotional abilities are influenced by parenting styles. Children with democratic parenting tend to be able to express their emotions appropriately and recognize the emotions of their friends. This research aims to develop the interactive games for early childhood. The method used is 4D (Diagnose, Design, Develop and Dessiminate). The results of this research, was found that $40 \%$ of children were authoritarian, $30 \%$ were with permissive parenting and $30 \%$ were with democratic parenting. Sex differences do not affect children's psycholinguistic abilities. What distinguishes only children who are well stimulated, the child's psycholiguistic abilities will develop well. Most of the children come from the lower middle class economy. Availability of digital facilities determines the level of digital literacy skills of children. Children who are accustomed to technology can easily run RPG games.
\end{abstract}

Keyword : Development, Role Play Game (RPG), Childhood

\section{Introduction}

Digital literacy in early childhood is a trend in the millennial era. This development is marked by the child's ability to recognize sounds and connect with digital signals. One of them is in the form of a Role Play Game (RPG) based Educational Game on the theme of animals for early childhood. Game interactions will stimulate imagination and visualize children's knowledge connections in the form of digitally recorded responses. However, there are not many RPG-based interactive games to improve early childhood digital literacy skills.

In the conditions of the Covid 19 pandemic, the development of interactive games for early childhood has become a solution for online learning and blended learning. So far, the development of interactive early childhood games is still limited to aspects of cognition or knowledge. In this research, game products are expected to be able to overcome literacy limitations, especially to see how early childhood responds to digital signals in the form of symbols and digital forms. This study aims to develop interactive RPG-based games that can improve early childhood digital literacy skills.

\section{Methodology}


This research uses a 4D development technique with Diganose, Design, Develop, and Dessiminate stages. The research sample is TK Fadhilah 3 dan TK Yayasan Wanita Kereta Api Kota Padang, West Sumatera, Indonesia.

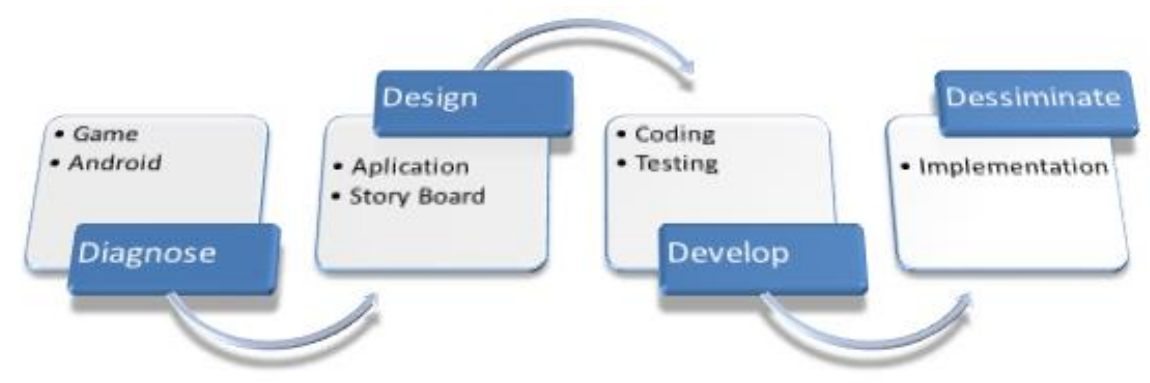

Fig. 1. Schematic of research step for making prototype of interactive games

Table 1. Research Instrument Gridpsycholunguisti

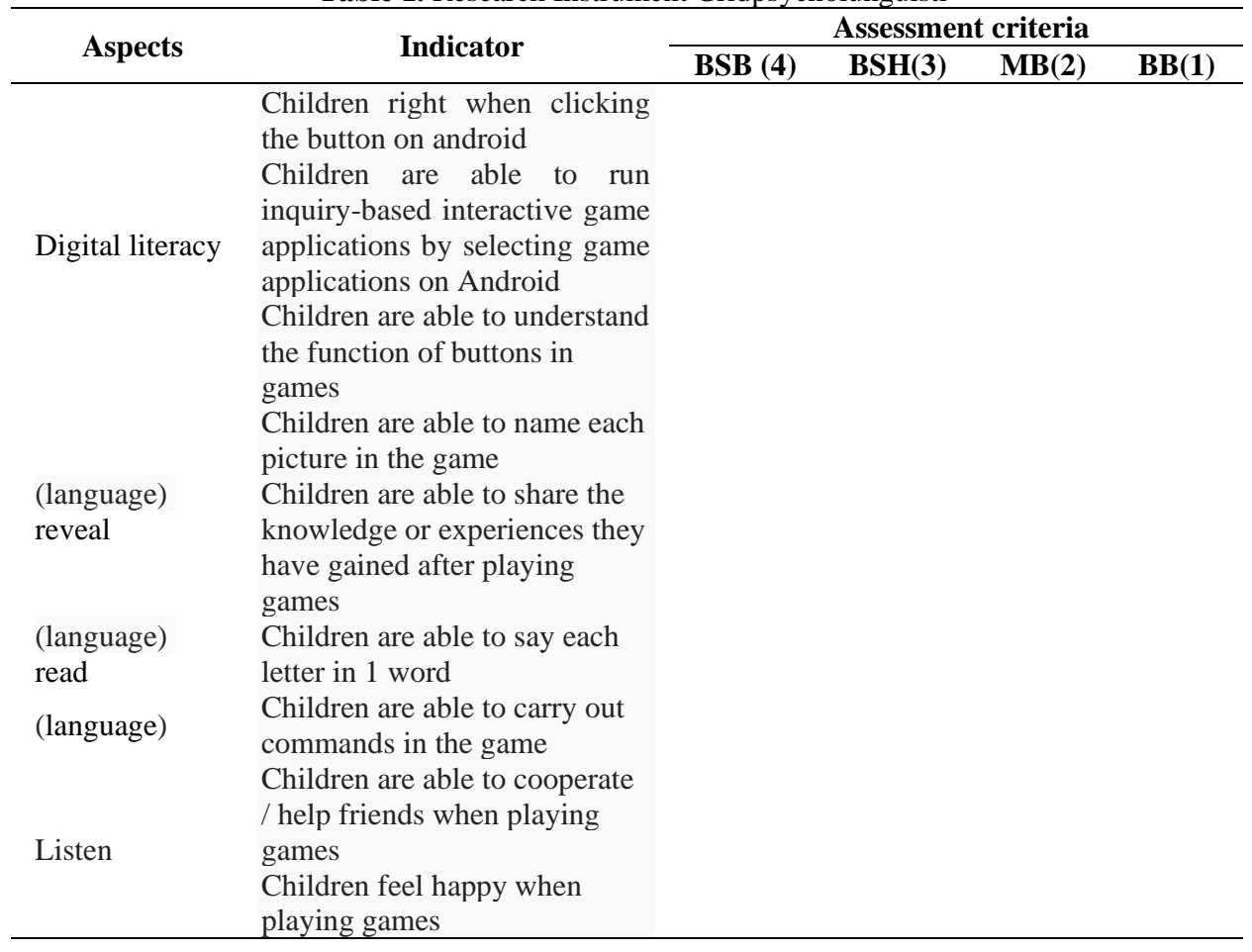

\section{Result and Discussion}

The resulting interactive game product has 2 levels of application. Level 1 to provide stimulation to digital visuals. At this stage, children will get experience to visually examine what they know about animal parts, then recognize them by giving signals. Response signals 
are given and recorded in the form of an active board game that the child can choose and click according to their thought processes and knowledge.

In stage two, the child will gain experience by recognizing the frequency pattern of the sound produced, then repeating it again. This is a step to make a decision to process sound stimuli into visual knowledge associated with the interactive games that are made. For example, the sound of a goat, it will show a goat and vice versa. This process is presented in an RPG game application to improve and develop children's digital knowledge and literacy.

\subsection{Product Implementation}

RPG-Based Interactive Game (Role Play Game) Inquiry Learning Model is a game that makes children active because it is interactive. The game will give a response every click in the form of a questioning voice, invite the child to spell letters or give rewards when the child finishes the game correctly. In addition, this game is very challenging for children because there are levels 1 to level 3 so there is a level of difficulty that the child must go through. This game aims to develop or stimulate Child Psycho-Linguistic Intelligence which includes the following:

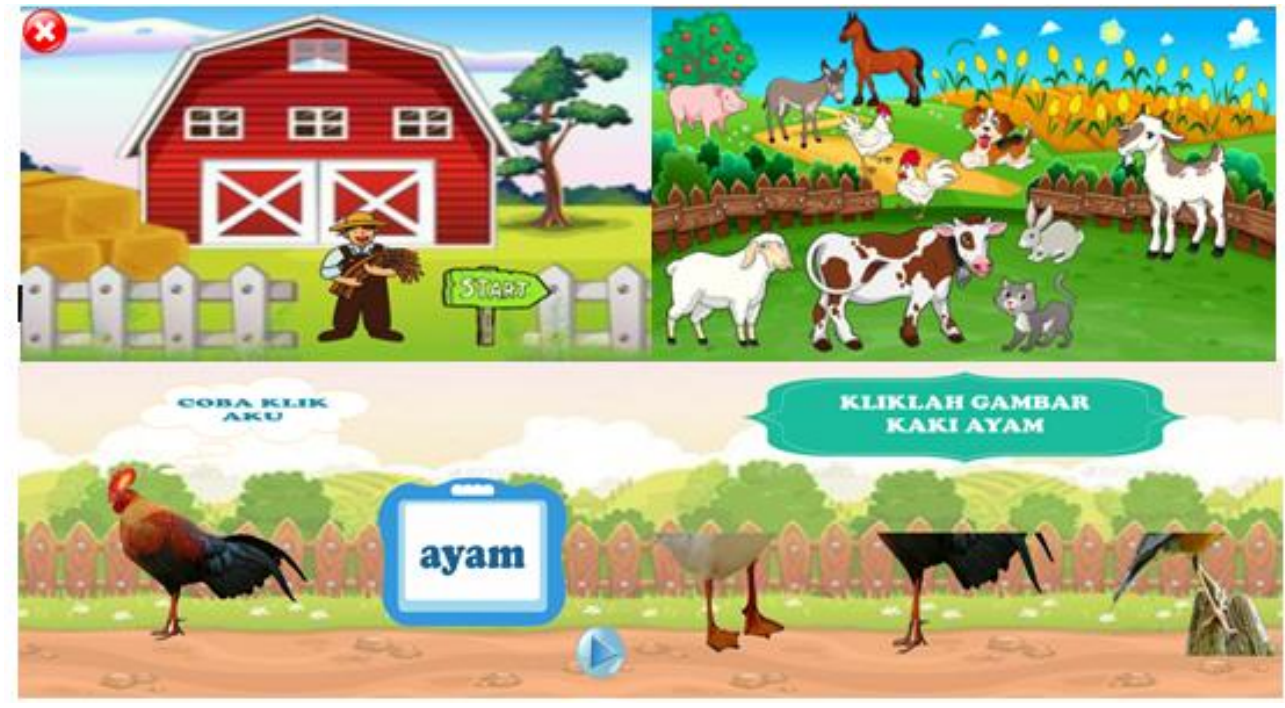

Fig. 2. Storyboard of the interactive game

Digital literacy (use of digital technology). Digital literacy skills of children develop when children run games using digital technology. Language (reading, expressing / telling stories, listening) (Core Competency 3 Knowledge in K13). Children's reading skills develop when children mention pictures and spell or recognize letters in the game, children's listening skills develop when children click a button in a game which then the game responds to questions that must be answered by children, children's storytelling skills develop when children recount their experiences during played.

Social emotional (social, emotional) (Core Competence 2 social in K13). Children's social emotional abilities develop when children take turns playing with their friends or in groups. In addition, children will feel happy or sad when they cannot finish the game. 
Table 2. Calculation Results of Post-test Testing with t-test

\begin{tabular}{ccccccc}
\hline No & Group & $\mathbf{N}$ & Mean & t Calc & t Table $\boldsymbol{\alpha ~ 0 , 0 5}$ & Decision \\
\hline $\mathbf{1}$ & Experiment & 10 & 82 & 3,439 & 2,100 & reject $\mathrm{H}_{0}$ \\
$\mathbf{2}$ & Control & 10 & 69 & & & \\
\hline
\end{tabular}

The comparison of the results of the calculation of the pre-test and post-test scores is seen in the highest and lowest scores obtained by the children and is seen in the average of the experimental class and the control class in the post-test where in the post-test the average is more increased than the average. pre-test after treatment.

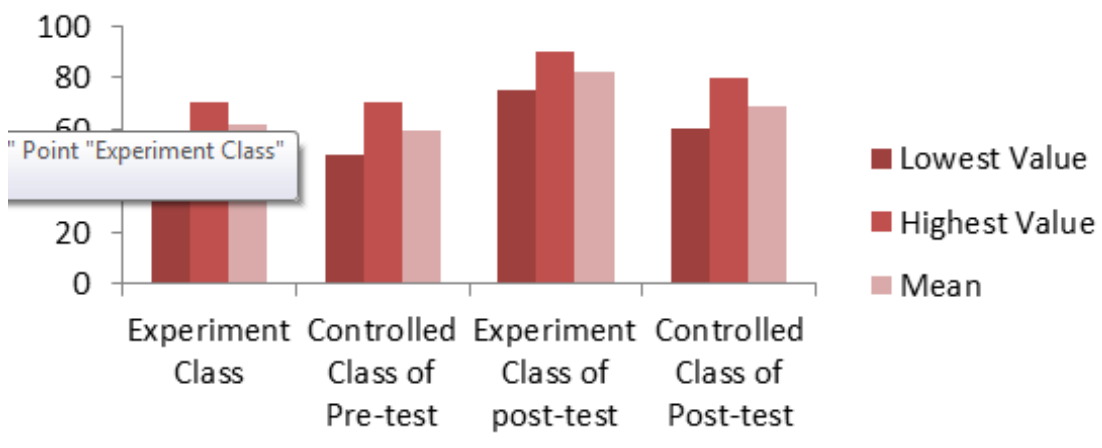

Figure 3. Data Comparison of Pre-Test and Post-Test Results of Reading Ability in Experiment Group and Control Group

From the research that the researchers conducted, it was seen the relationship between the pre-test and post-test results. The pre-test results show that the average of the experimental class is 61.5 and the average control class is 59. After being given the treatment, it can be seen that the post-test results of the reading ability in the experimental class using RPG-Based Interactive Games (Role Play Games) are further increased An average of 82 while the control class using Game Power Point got an average of 69. It can be concluded that there is a comparison of the pre-test and post-test results of the reading ability of the experimental group and the control group. Thus it is proven that the Interactive Game Based on RPG (Role Play Game) is Effective for Reading Ability in Fadhilah Amal 3 Kindergarten, Padang.

Based on the results of the study, it was found that children are very interested when technological media are used in learning. RPG-based interactive games are able to develop children's psycholungistic abilities such as language skills and children's social emotional. In addition, an interest in technology can stimulate children to improve their ability to use technology (Digital Literacy) so that they are able to run games. An RPG-based interactive game is a game that stimulates children to be active in the learning process so that the delivery of knowledge in the game is conveyed in a way that is fun for children.

The obstacle that occurred during the research was the lack of facilities to access the game so that children had to wait a long time for their turn. In addition, the concept of the existence of games has been embedded in children only to play without educational elements so that when the children are used, they only focus on how the game will finish immediately without solving problems first. It takes a while to get the child to run the game without haste so that the child's psycholungistic abilities develop 


\section{Conclusion}

Children's social emotional abilities are influenced by parenting styles. Children with democratic parenting tend to be able to express their emotions appropriately and recognize the emotions of their friends. For social skills, children with democratic parenting are able to communicate and express opinions well so that they can interact with their friends. It was found that $40 \%$ of children were authoritarian, $30 \%$ were with permissive parenting and $30 \%$ were with democratic parenting. Sex differences do not affect children's psycholinguistic abilities. What distinguishes only children who are well stimulated, the child's psycholiguistic abilities will develop well. Most of the children come from the lower middle class economy. Availability of digital facilities determines the level of digital literacy skills of children. Children who are accustomed to technology can easily run RPG games. 